masterly essays upon these and others to the Linnean Society. His treatises on the Leguminosæ are no less exhaustive and valuable; and there is not a temperate or tropical region of the globe whose floras have not been largely elucidated by him. It may safely be affirmed that for variety and extent of good work of the kind he had no superior. The distinctive qualities of his descriptions are-scientific accuracy, good arrangement, precision of language, lucidity, and the discarding of what is superfluous. In these respects he has had no superior since the days of Linnæus and Robert Brown, and he has left no equal except Asa Gray.

of his amiable disposition, and his sterling qualities of head and heart, it is impossible to speak too highly: though cold in manner and excessively shy in disposition, he was the kindest of helpmates and most disinterested of labourers for others.

Of recognition by foreign Academies Bentham had his full share, including that of Corresponding Member of the Institute of France. His election into the Royal Society was not till late (1862). It should have been in $\mathrm{I} 829$, when he was proposed by $\mathrm{R}$. Brown, and at his recommendation withdrawn, along with other scientific candidates, who thus showed their dissatisfaction at the Society's election of a Royal Duke to the President's chair. He, however, received the Royal Medal of the Society, and in 1878 , on the completion of the Australian flora, the Secretary of State for the Colonies, unsolicited, recommended him to Her Majesty for the Companionship of the Order of St. Michael and St. George.

\section{A MODEL LENS FOR USE IN CLASS DEMONSTRATIONS}

I $\mathrm{N}$ using diagrams or models as aids in teaching, this question constantly arises-- How far may we represent Nature diagrammatically without producing in the mind of a student one-sided and false impressions? I have myself endeavoured to follow this rule: that, if a complicated object or phenomenon is to be studied, we may simplify this, and bring out many salient features, with a diagrammatic representation ; this must, however, only be looked upon as a stepping-stone to a more complete study of the object or phenomenon itself. The

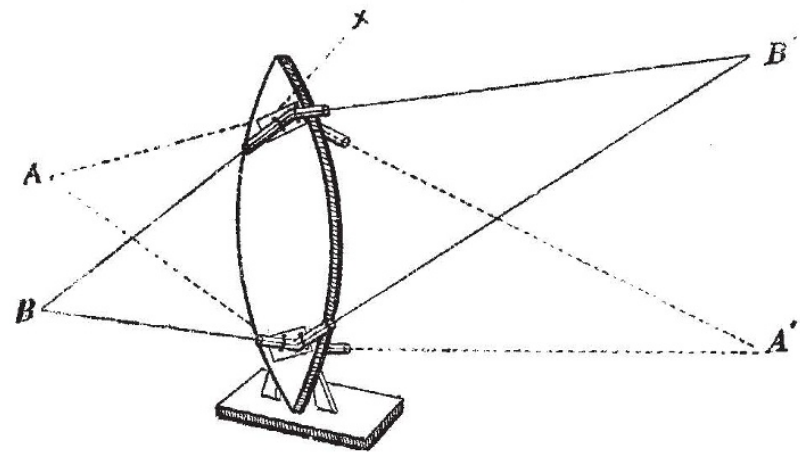

model of a lens to be described I have found of much service in lecturing, anteccdent to a demonstration of the passage of luminous rays through actual lenses.

This model may be constructed out of the simplest materials, and should cost but two or three shillings. It consists of a piece of deal board cut in the shape of the cross-section of a biconvex lens, and fixed to a stand of wood (sce diagram). Four small squares of board, $x$, are fixed in the positions indicated, two on either side of the lens. Glass tubes bent at obtuse angles are fixed to these by staples, and can rotate with them on the screws by means of which the squares are fixed to the lens. Two bieces of string to represent visual rays are then passed ti.rough the tubes $\mathrm{A} \mathrm{A}^{\prime}$ and $\mathrm{B} \mathrm{B}^{\prime}$. The theory of the use of this model will be at once apparent. A ray of light passing through a lens of a given curvature and density will practically (this is not absolutely true) be bent at a given angle, whatever be the direction of the ray, so long as it passes through the same part of the lens. In the model this constant degree of bending is given to the string-representing the ray of light--by the bent tubes. These, rotating on the lens, allow one diagrammatically to represent the rays passing through it in any desired direction.

Taking the string $\mathrm{B} \mathrm{B}^{\prime}$, for example, and holding it at these two points in the two hands, and keeping the string taut, it will be found that in shifting the point $\mathrm{B}$-representing a luminous point--in any direction, $\mathrm{B}^{\prime}$ will shift until it occupies the position of the corresponding focus. By shifting the string it is possible to demonstrate the focal points of parallel, diverging, and converging rays, either parallel to the axis of the lens, or on secondary axes. Then, by using at the same time the string fixed to the other side of the lens $\mathrm{AA}^{\prime}$, the formation of an image may be shown. Grasping with the two hands $A$ and $B$, an assistant holding $A^{\prime}$ and $B^{\prime}$, it will be seen how by this lens an inverted image is produced. Bring the points $\mathrm{A}$ and $\mathrm{B}$ nearer the lens, keeping them, how ever, at the same distance apart, and the points $A^{\prime}$ and $B^{\prime}$ will recede from the lens and from each other, showing how the image of the nearer object is formed farther away from the lens, and is larger in size. On the other hand, if $\mathrm{A}$ and $\mathrm{B}$ be pulled away from the lens, $\mathrm{A}^{\prime}$ and $\mathrm{B}^{\prime}$ approximate to it and to one another.

In working the model the squares should rotate easily, and the strings must always be held taut. For lectureroom purposes the lens should be about two feet high, and the strings may be coloured. On the same principle I have constructed models of other lenses or lens combinations.

Physiological Laboratory, Mason College, Birmingham

\section{THE ELECTRICAI EXHIBITION AT PHILADELPHIA}

[FROM A CORRESPONDENT]

$\mathrm{TO}$

one who has visited the various electrical exhibitions held in recent years in the chief European cities, the Exhibition now open in the city of Philadelphia might seem a little disappointing from the absence of novelty in the exhibits, though replete with objects of interest for all to whom this class of show is not familiar. As might be expected, the strong point of the Philadelphia show is electric lighting; and the building-a temporary structure erected close to the depot of the Pennsylvania Railroad Company on the west bank of the Schuylkill-presents both interiorly and exteriorly a blaze of light. The array of dynamo-machines is remarkably complete. Edison leads the way with a variety of machines, including one "Jumbo," of the same type as, but rather smaller than, the pair of machines in use at the Holborn Viaduct lighting station. There are also a large number of Weston's machines, and a very valuable exhibit by the Thomson-Houston Company. The machines of the latter company are quite unique amongst dynamos; one of them can maintain sixty arc lights on one circuit, though there are but three coils on its armature. Other dynamos are shown by Ball, Hockhausen, Van Depoele, and McTighe. There are several excellent arc lamps, possessing novelty, however, in matters of detail only. A great show of incandescent lamps is made by the Edison Company, and also by the Weston Company. The latter has some remarkable lamps with filaments sixteen inches in length prepared from a new parchment-like substance, of which samples are shown. These lamps are from Ioo to 200 reputed candle power.

Electric motors are exhibited by several inventors. 